\title{
An Akan Translation, Validation and Reliability of a Questionnaire for assessing Awareness of Ghanaian women on Prostate Cancer
}

\author{
Ebenezer Wiafe, ${ }^{1,3}$, Kofi Boamah Mensah ${ }^{1,2}$, Adwoa Bemah Boamah Mensah², \\ Varsha Bangalee ${ }^{1}$, Frasia Oosthuizen ${ }^{1}$
}

${ }^{1}$ Discipline of Pharmaceutical Sciences, University of KwaZulu-Natal, Durban, South Africa ${ }^{2}$ Kwame Nkrumah University of Science and Technology, Kumasi, Ghana. ${ }^{3}$ Clinical Pharmacy Services Unit, Ho Teaching Hospital, Ho, Ghana.

\begin{abstract}
Objectives: The study aimed to: (1) adopt, modify and develop a questionnaire suitable for data collection on prostate cancer in the female population, (2) translate the questionnaire into the Akan language, and (3) conduct a validity and reliability analysis on the Akan questionnaire. Methods: An English version questionnaire was developed and adequately translated into an Akan version according to the forward and backward translation protocols. The Akan questionnaire went through translator-approval and certification. Validity and reliability analysis were performed on the questionnaire. Statistical analysis for face validity involved the determination of average scores while content validity involved the determination of the content validity index. Regarding reliability analysis, Cronbach's alpha was calculated for the test and retest periods of study. Results: A forty-five (45) membered Akan questionnaire was successfully developed and certified. The average scores for all parameters employed in the face validation were greater than 4 . The content validity index was within the range of $0.90-0.99$ while the Cronbach's alpha for both test periods was within the range of $0.7808-0.9209$. Conclusion: The Akan questionnaire had acceptable validity and reliability outcome. Therefore, the questionnaire was considered appropriate for assessing knowledge, awareness, and perception of Ghanaian women of prostate cancer.
\end{abstract}

Keywords: Akan questionnaire- Translation- Validity analysis- Reliability analysis- Knowledge- Awareness- Perception

Asian Pac J Cancer Care, 6 (3), 257-262

\section{Introduction}

The promotion of family health is attributed to women, including the wellbeing of their acquaintances $[1,2]$. A study conducted in North America stressed the influence women have on their relatives regarding their health-seeking demeanour [3]. Other roles women have been shown to play towards health promotion includes the provision of health-related advice, their acting as advocates for various medical conditions including cancers, and their unique role in providing support for the sick [4]. According to Taylor and colleagues, husbands confirmed soliciting for health information from their significant others [5]. Therefore, there is evidence to support the crucial role women could play towards the early detection of prostate cancer $(\mathrm{PCa})$.
Submission Date: 01/30/2021 Acceptance Date: 04/23/2021

\footnotetext{
Corresponding Author:

Dr. Ebenezer Wiafe

${ }^{1}$ Discipline of Pharmaceutical Sciences, University of KwaZulu-Natal, Durban, South Africa. ${ }^{3}$ Clinical Pharmacy Services Unit, Ho Teaching Hospital, Ho, Ghana.

Email:weben38@gmail.com
} 
(2) to translate the questionnaire into the Akan language, and (3) to conduct a validity and reliability analysis on the Akan questionnaire.

\section{Materials and Methods}

The methodology behind the study is summarized as a flowchart in Figure 1.

\section{Development of the English Version Questionnaire}

The English version questionnaire was adopted from a study by Otoo when she undertook a study on prostate cancer awareness in Ghanaian military men [10]. The questionnaire was modified with inputs from a study conducted by Blanchard et al. [3]. The developed questionnaire was submitted to the Committee on Human Research, Publications and Ethics (CHRPE) and the Biomedical Research Ethics Committee (BREC) of the authors' institutes. The CHRPE accepted and approved the questionnaire whilst a recommendation from BREC to reduce questionnaire length informed the final English version of the questionnaire. The English version questionnaire was resubmitted to BREC for approval.

\section{Forward Translation and Approval}

The approved English version was subjected to a forward translation into Akan. The forward translation entails converting a document from an original language into a second language of interest $[11,12]$. Three translators with academic degrees in the Akan language and fluent in the English language translated the English version into the Akan version. The translators considered the Akan version for approval. English words, such as the prostate that did not have literal meanings in the Akan language were adequately given descriptions as previously done in a study by Nejjari et al. [13].

\section{Backward Translation and Approval}

The Akan version of the questionnaire was backtranslated into the English language by three translators with academic degrees in the English language and fluent in the Akan language. This method was by similar studies involving the translation of questionnaires into different native languages $[11,12]$. The translators considered the back-translated English version for approval.

\section{Assessment, Approval, and Certification}

The backward translation version, which is the second English version, was assessed by the six (6) independent translators. The assessment involved a thorough comparison of the second English version to the ethicallyapproved English version for conceptual agreement [11]. The forward translation version, which is the Akan version, was further assessed by the six (6) independent translators and considered for translator-approval before submission for certification.

\section{Questionnaire Validation}

The variables of the construct of the Akan questionnaire was assessed for face and content validity $[12,14]$.
Content validity is the extent to which a set of variables comprehensively covers the different components of the questionnaire [15]. On the contrary, face validity is whether the questionnaire's variables are appropriate, sensible, and suitable to the population intended for use [16].

\section{Face validation}

Face validation must preferably be performed by non-experts participants on the construct being studied [14]. It is the simplest validation method and the weakest type of validity [14]. In a study by Sowtali et al. ten (10) non-experts (stroke patients) were employed in the face validation [14]. To ensure the same number of individuals were employed in the translation, face validation, and content validation processes, six (6) market women fluent in the Akan language were randomly selected to evaluate the Akan questionnaire for face validity. The market women scored, on a scale of 6 (very week, week, moderately week, good, very good, excellent) [17], the 45 variables of the Akan questionnaire according to language appropriateness, clarity and cultural acceptance $[11,14]$. The average points scored by the market women were computed into excel [17].

\section{Content validation}

The content validation focused on the relevance of the questionnaire to the study and the questionnaire's ability to measure the study construct $[12,14]$. Six (6) experts adequately assessed the content validity of the questionnaire items [12]. Typically, 5 to 7 experts are used to evaluate whether the variables of interest are well represented in the questionnaire [18]. Therefore, two pharmacists with the Doctor of Pharmacy and Master's degree in clinical pharmacy, two oncology nurses, and two clinical oncologists at the Komfo Anokye Teaching Hospital (KATH), Ghana, scored the questionnaire. Items of the questionnaire were scored on a scale of three (3) (poor, moderate, good) according to the relevance of the items to the study [17]. The Content Validity Index (CVI) was determined and computed [14].

\section{Reliability Assessment}

The Akan questionnaire reliability was assessed to verify the tool's ability to measure the domains of the study according to the test-retest method at an interval of seven (7) days [17, 19]. Retesting was relevant in reducing the order effect [17]. It also measures the test's internal validity and ensures that the results obtained are reliable and can replicate itself repeatedly in the same population and situation. The duration of the test-retest was 14 days.

\section{Population}

A portion of the female traders on the ground floor of the Kumasi Central Market, also known as the Kejetia Market, located in the Ashanti region of Ghana, was employed in the reliability study. Only women who consented to the study and volunteered to be available for the retest period were recruited. Women below 18 years and female mobile traders were excluded. 
Sample size and sampling technique

According to the administrative manager, the market holds about 25,000 female traders. In determining sample size for a conventional study at a confidence level (c) of 95\%; a precision level (e, sampling error) of $+/-5 \%$ and a degree of variability (p) of 50\%; an estimated sample size of 400 is recommended according to published tables by Israel [20]. For the reliability study, 100 women ( $25 \%$ of the recommended sample size) were recruited. To obtain an intra-class correlation coefficient (ICC) of not less than $0.75 \pm 0.1$ at a $95 \%$ confidence interval, a sample size of 51 is appropriate [19]. Other studies recruited a lesser sample size [14] and relatively higher sample sizes [17, 19].

To reduce bias and ensure an equal chance of participation, the women were simply and randomly sampled [21]. The ground floor of the market was divided into four (4) sections and each section into five (5) sub-sections. Five (5) women were randomly selected per sub-section and considered for inclusion.

\section{Statistical analysis}

STATA software was employed for statistical evaluation. The internal reliability of the Akan questionnaire was measured using Cronbach's alpha $[17,19]$. To measure the constructs of face validity, descriptive statistics were used.

\section{Results}

\section{Translation Outcome}

A sixty-one (61) items questionnaire was adopted and adapted (Appendix 1). The questionnaire was modified to forty-five (45) (Appendix 2) in response to BREC. The forward and backward translations were approved by the respective translators. The translator-approved English version questionnaire was found to be conceptually equivalent to the original English version questionnaire. The Akan version (Appendix 3) was approved by all the six (6) independent translators. The translator-approved Akan version was certification.

\section{Validity Analysis Outcome}

The face validity scores have been computed in Table 1 . The questionnaire, taking all the various sections into account, had an average validity score range of 4.17 $6.00(4.73 \pm 0.90)$ on language appropriateness; 4.33 - 6.00 $(5.04 \pm 0.76)$ on clarity; and 4.17- $5.83(5.11 \pm 0.86)$ on cultural acceptance.

The Content Validity Index (CVI) has been presented (Table 2). The various sections of the questionnaire had a lower limit CVI greater than 0.75 except for section $6 \mathrm{~B}$, beliefs about prostate cancer, which had a CVI range of $0.73-1.00(0.91 \pm 0.44)$. A CVI range of $0.90-0.99$ $(0.96 \pm 0.32)$ was obtained for the complete questionnaire.

Table 1. Face Validity Results

\begin{tabular}{lcccccc}
\hline Sections & \multicolumn{2}{c}{ Language Appropriateness } & \multicolumn{2}{c}{ Clarity } & \multicolumn{2}{c}{ Cultural Acceptance } \\
& $\begin{array}{c}\text { Average score } \\
\text { (range) }\end{array}$ & Mean \pm SD & $\begin{array}{c}\text { Average score } \\
\text { (range) }\end{array}$ & Mean \pm SD & $\begin{array}{c}\text { Average score } \\
\text { (range) }\end{array}$ & Mean \pm SD \\
\hline 1 & $4.17-4.83$ & $4.44 \pm 0.93$ & $4.33-5.33$ & $4.69 \pm 0.78$ & $4.67-5.33$ & $5.17 \pm 0.93$ \\
2 & $4.33-5.00$ & $4.60 \pm 0.93$ & $4.50-5.17$ & $4.81 \pm 0.78$ & $4.67-5.67$ & $4.98 \pm 0.90$ \\
3 & $4.33-5.17$ & $4.72 \pm 0.87$ & $4.50-5.33$ & $5.06 \pm 0.68$ & $4.33-5.67$ & $5.15 \pm 0.78$ \\
4 & $4.33-4.67$ & $4.53 \pm 0.85$ & $4.67-5.00$ & $4.80 \pm 0.75$ & $4.33-5.33$ & $4.77 \pm 0.84$ \\
5 & $4.50-5.33$ & $4.67 \pm 0.77$ & $4.67-5.50$ & $5.17 \pm 0.78$ & $4.17-5.33$ & $4.88 \pm 0.91$ \\
6 A & $4.50-6.00$ & $5.00 \pm 0.93$ & $5.16-6.00$ & $5.47 \pm 0.56$ & $5.33-5.83$ & $5.67 \pm 0.54$ \\
6 B & $4.67-5.50$ & $5.17 \pm 0.86$ & $5.17-5.67$ & $5.40 \pm 0.55$ & $5.33-5.50$ & $5.33 \pm 0.75$ \\
Score (all sections) & $4.17-6.00$ & $4.73 \pm 0.90$ & $4.33-6.00$ & $5.04 \pm 0.76$ & $4.17-5.83$ & $5.11 \pm 0.86$ \\
\hline
\end{tabular}

Table 2. Content Validity Results

\begin{tabular}{lcc}
\hline Sections & \multicolumn{2}{c}{ Relevance of Variables to Study } \\
& Content Validity Index (CVI) range & Mean \pm SD \\
\hline 1 & $0.89-1.00$ & $0.96 \pm 0.31$ \\
2 & $0.92-0.96$ & $0.95 \pm 0.35$ \\
3 & $0.93-1.00$ & $0.97 \pm 0.29$ \\
4 & $0.93-1.00$ & $0.99 \pm 0.18$ \\
5 & $0.95-1.00$ & $0.99 \pm 0.15$ \\
$6 \mathrm{~A}$ & $0.80-1.00$ & $0.93 \pm 0.40$ \\
$6 \mathrm{~B}$ & $0.73-1.00$ & $0.91 \pm 0.44$ \\
CVI (all sections) & $0.90-0.99$ & $0.96 \pm 0.32$ \\
\hline
\end{tabular}




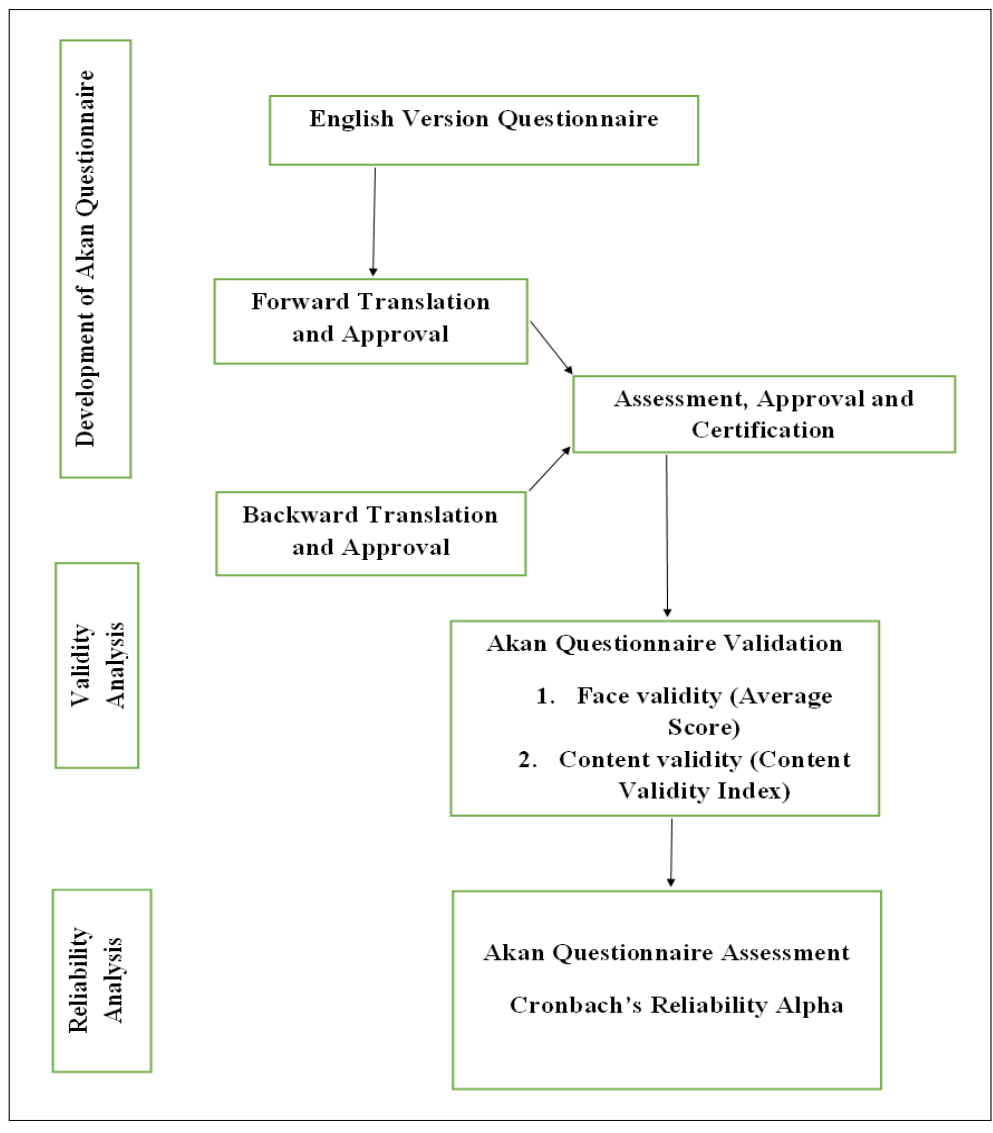

Figure 1. A Flowchart Illustrating the Translation, Validity and Reliability Analysis Methodology

\section{Reliability Analysis Outcome}

The socio-demographics of the participants are presented in Table 3 . The age of participants ranged from $18-72$ years $(41.96 \pm 15.288$ for the test, and $42.17 \pm$ 15.154). The leading socio-demographical classes were; married reflecting marital status, primary reflecting highest educational level, Christianity to religion, Akan under the major ethnic group section, and nonmembership of market associations.

Cronbach's alpha values obtained in determining the internal reliability of the Akan questionnaire are reported in Table 4. Alpha values for the various sections of the questionnaire, taking into account the test and retest periods, were above 0.5 except section 6 . For the two sections of the questionnaire that evaluated the perception of women on prostate cancer, the sub-section on women's attitudes towards prostate cancer had a Cronbach's alpha of 0.4637 at baseline and 0.2314 for the retest. Cronbach's alpha of the sub-section that evaluated beliefs about prostate cancer was 0.2211 at baseline and increased to 0.3427 during the retesting period. The overall Cronbach's alpha for all the variables, grouped and ungrouped, for the test and retest was within the range of $0.7808-0.9209$.

\section{Discussion}

The Akan questionnaire was developed to assess the knowledge, awareness, and perception of women towards prostate cancer. The questionnaire is hoped to aid in studies aimed at equipping Ghanaian women to contribute to the early detection of prostate cancer. The translation procedure was successful and received adequate certification. The face and content validation were performed on the Akan version to assess the feasibility of questionnaires to adequately measure the study construct of interest and determine the relevance of variables to the study [14]. The reliability analysis was performed to determine the Akan questionnaire's ability to adequately measure the domains of the study [12].

According to Nahad et al. face validity scores greater than 4 , on a scale of 6 , reflect an excellent questionnaire validity [17]. On a scale of 5, scores of 3 and 4 , respectively represent adequate and very suitable absolute face validity [22]. From the results (Table 1), all sections of the questionnaire had an average validity score greater than 4 for language appropriateness, clarity, and cultural acceptance. Therefore, the questionnaire had good face validity. The results further affirm the ability of the Akan questionnaire to measure the study construct of interest adequately.

From the submission of Yaghmaei, a content validity index (CVI) greater than 0.75 describes a good content validity outcome [23]. Some studies have successfully evaluated the content validity of questionnaires according to the recommendation of Yaghmaei [14, 17]. In general, the questionnaire exhibited a good content validity outcome as a CVI range of $0.90-0.99(0.96 \pm 0.32)$ was 
Table 3. Demographical Features of Study Subjects $(\mathrm{n}=100)$

\begin{tabular}{|c|c|c|}
\hline Variable & Test & Retest \\
\hline Age $($ Mean \pm SD $)$ & $41.96 \pm 15.288$ & $42.17 \pm 15.154$ \\
\hline Age (Minimum) & 18 & 18 \\
\hline Age (Maximum) & 72 & 72 \\
\hline \multicolumn{3}{|l|}{ Age (Ranges) } \\
\hline $15-19$ & 2 & 2 \\
\hline $20-24$ & 18 & 17 \\
\hline $25-29$ & 9 & 9 \\
\hline $30-34$ & 8 & 8 \\
\hline $35-39$ & 4 & 4 \\
\hline $40-44$ & 11 & 12 \\
\hline $45-49$ & 17 & 17 \\
\hline $50-54$ & 9 & 9 \\
\hline $55-59$ & 5 & 5 \\
\hline $60+$ & 19 & 19 \\
\hline \multicolumn{3}{|l|}{ Marital Status } \\
\hline Married & 47 & 49 \\
\hline Never married & 25 & 25 \\
\hline Cohabiting & 8 & 7 \\
\hline Widowed & 15 & 14 \\
\hline Divorced/Separated & 5 & 5 \\
\hline \multicolumn{3}{|l|}{ Highest Educational level } \\
\hline Primary & 46 & 50 \\
\hline Secondary & 35 & 32 \\
\hline Tertiary & 11 & 10 \\
\hline No education & 8 & 8 \\
\hline \multicolumn{3}{|l|}{ Religious Affiliation } \\
\hline Christianity & 92 & 92 \\
\hline Islamic & 7 & 7 \\
\hline other & 1 & 1 \\
\hline \multicolumn{3}{|l|}{ Ethnic Background } \\
\hline Akan & 90 & 90 \\
\hline Mole-Dagbane & 2 & 2 \\
\hline Other & 8 & 8 \\
\hline \multicolumn{3}{|l|}{ Market Association } \\
\hline Hair Sellers & 1 & 1 \\
\hline Kejetia Market Union & 1 & 1 \\
\hline Make-Up Sellers & 2 & 2 \\
\hline Petty Traders & 1 & 1 \\
\hline None & 95 & 95 \\
\hline
\end{tabular}

calculated. Although section $6 \mathrm{~B}$ of the questionnaire had a lower limit CVI of 0.73 , the mean was found to be 0.91 and could be generally considered a good content validity outcome.

According to Sowtali et al., Cronbach's alpha values between 0.5 to 0.7 are acceptable, while values of 0.7 and higher reflect apparent questionnaire items homogeneity [14]. The Cronbach's alpha values of sections 6A(0.4637 for test and 0.2314 for retest) and $6 \mathrm{~B}(0.2211$ for test and 0.3427 for retest) were below the lower acceptable limit. However, the overall Cronbach's alpha for all the variables, grouped and ungrouped, exhibited an acceptable internal reliability and questionnaire items homogeneity as outcomes for both test and retest were within the range of 0.7808 - 0.9209. Therefore, the Akan questionnaire has acceptable internal reliability and homogeneity.

In conclusion, the Akan version of the questionnaire was successfully developed and certified. The outcomes of the validity and reliability analysis of the questionnaire were acceptable. It is recommended that the questionnaire be used to study the knowledge, awareness, and perception of Ghanaian women about prostate cancer. Also, a more robust psychometric analysis, not limited to the Exploratory and Confirmatory Factor Analysis, must be performed. Given these recommendations, the Akan tool could adequately study prostate cancer awareness in Ghanaian women. Furthermore, the psychometric analysis would increase the acceptability of the developed tool.

\section{Study Limitations}

1. The questionnaire validity and reliability analysis was restricted to the Kejetia Market and did not include Ghanaian women from other places in the country.

2 . The validation process was limited to the face and content validation methods and did not include a robust psychometric analysis such as the Exploratory and Confirmatory Factor Analysis.

3. The reliability analysis was restricted to the evaluation of only internal reliability.

\section{Availability of data and materials}

Data and other materials are available at; https://doi. org/10.17605/OSF.IO/9GZTD

\section{Authors' Contributions}

EW is credited with the study conception, methodological development, data collection, analysis and interpretation of data, study coordination, statistical analysis, drafting of the manuscript, and material support. KBM is credited with the study conception, methodological development, statistical analysis, critical review of the manuscript for important intellectual content, and supervision. ABBM is credited with the statistical analysis, and critical review of the manuscript for important intellectual content. VB is credited with the critical revision of the manuscript for important intellectual content, and supervision. FO is credited with the critical revision of the manuscript for important intellectual content, and supervision. All authors read and approved the manuscript for publication.

\section{Ethical consideration}

Ethical approval was obtained from the Committee on Human Research, Publications and Ethics (CHRPE) of the Kwame Nkrumah University of Science and Technology (KNUST), and the Biomedical Research Ethics Committee (BREC) of the University of KwaZuluNatal (UKZN). The respective approval references are CHRPE/AP/127/20 and BREC/00001292/2020. 
Table 4. Cronbach's Reliability Test

\begin{tabular}{lcc}
\hline Sections & Test & Retest \\
\hline 2. Awareness about prostate cancer & 0.6161 & 0.5486 \\
3. Knowledge on signs and symptoms of prostate cancer & 0.9364 & 0.8883 \\
4. Knowledge on the causes of prostate cancer & 0.707 & 0.7005 \\
5. Knowledge on the risk factors of prostate & 0.7749 & 0.6634 \\
6A. Attitude towards prostate cancer & 0.4637 & 0.2314 \\
6B. Beliefs about prostate cancer & 0.2211 & 0.3427 \\
Cronbach's alpha for all variables (grouped into sections) & 0.8101 & 0.7808 \\
Cronbach's alpha for all variables (ungrouped) & 0.9209 & 0.8892 \\
\hline
\end{tabular}

\section{Acknowledgments}

The research team gives recognition to Prof. Charles Marfo for translation certification. Also, the team appreciates the market women of the Kejetia Market for consenting to the study.

\section{References}

1. Stoller EP. Gender and the organization of lay health care: A socialist-feminist perspective. Journal of Aging Studies. 1993 06;7(2):151-170. https://doi.org/10.1016/08904065(93)90031-e

2. Norcross W, Ramirez C, Palinkas L. The influence of women on the health care-seeking behavior of men. Journal of Family Practice. 1996;43(5):475-80.

3. Blanchard K, Proverbs-Singh T, Katner A, Lifsey D, Pollard S, Rayford W. Knowledge, attitudes and beliefs of women about the importance of prostate cancer screening. Journal of the National Medical Association. 2005;97(10):1378-85.

4. Miller SM, Roussi P, Scarpato J, Wen K, Zhu F, Roy G. Randomized trial of print messaging: the role of the partner and monitoring style in promoting provider discussions about prostate cancer screening among African American men. Psycho-Oncology. 2013 Oct 15;23(4):404-411. https:// doi.org/10.1002/pon.3437

5. Taylor KL, Turner RO, Davis JL, Johnson L, Schwartz MD, Kerner J, Leak C. Improving knowledge of the prostate cancer screening dilemma among African American men: an academic-community partnership in Washington, DC. Public Health Reports. 2001 Nov;116(6):590-598. https:// doi.org/10.1016/s0033-3549(04)50092-4

6. Okoro ON, Rutherford CA, Witherspoon SF. Leveraging the Family Influence of Women in Prostate Cancer Efforts Targeting African American Men. Journal of Racial and Ethnic Health Disparities. 201708 25;5(4):820-830. https:// doi.org/10.1007/s40615-017-0427-0

7. Owens O, Jackson D, Thomas T, Friedman D, Hébert J. Prostate cancer knowledge and decision making among African-American men and women in the southeastern United States. International journal of men's health. 2015;14(1):55.

8. Anyidoho A, Dakubu M. Ghana: indigenous languages, English, and an emerging national identity. Language and national identity in Africa. 2008;141-57.

9. Sadat M, Kuwornu M. Views from the Streets of Accra on Language Policy in Ghana. Journal of Education and Practice. 2017;8(2):185-92.

10. Otoo V. Awareness of Prostate Cancer among male soldiers in the Ghana Armed Forces: University of Ghana; 2010.

11. Basim H, Sesen H, Korkmazyurek H. A Turkish translation, validity and reliability study of the dimensions of the learning organization questionnaire. World Applied Sciences Journal. 2007;2(4):368-74.

12. Arip MASM, Saad FM, Rahman AMA, Salim SSS, Bistaman MN. Translation, Validity and Reliability of Multidimensional Self-concept Scale (MSCS) Questionnaire among Malaysian Teenagers. Procedia - Social and Behavioral Sciences. 2013 07;84:1455-1463. https://doi. org/10.1016/j.sbspro.2013.06.773

13. Nejjari C, El Fakir S, Bendahhou K, El Rhazi K, Abda N, Zidouh A, Benider A, Errihani H, Bekkali R. Translation and validation of European organization for research and treatment of cancer quality of life Questionnaire -C30 into Moroccan version for cancer patients in Morocco. BMC Research Notes. 2014;7(1):228. https://doi. org/10.1186/1756-0500-7-228

14. Sowtali SN, Yusoff DM, Harith S, Mohamed M. Translation and validation of the Malay version of the Stroke Knowledge Test. Journal of Arrhythmia. 2016 04;32(2):112-118. https:// doi.org/10.1016/j.joa.2015.10.003

15. Fitzpatrick P. Evaluating patient-based outcome measures for use in clinical trials. Health Technol Assessment. 1998;2:14.

16. Holden R. Face validity. The corsini encyclopedia of psychology. 2010;1-2.

17. Nahad H, Rouzbahani M, Jarollahi F, Jalaie S, Pourbakht A, Mokrian H, et al. Translation, validity, and reliability of a persian version of the iowa tinnitus handicap questionnaire. Iranian journal of otorhinolaryngology. 2014;26(75):79.

18. Haynes SN, Richard DCS, Kubany ES. Content validity in psychological assessment: A functional approach to concepts and methods.. Psychological Assessment. 1995 09;7(3):238247. https://doi.org/10.1037/1040-3590.7.3.238

19. Rogers KD, Pilling M, Davies L, Belk R, Nassimi-Green C, Young A. Translation, validity and reliability of the British Sign Language (BSL) version of the EQ-5D-5L. Quality of Life Research. 201602 18;25(7):1825-1834. https://doi. org/10.1007/s11136-016-1235-4

20. Israel G. Determining sample size. 1992.

21. Singh A, Masuku M. Sampling techniques \& determination of sample size in applied statistics research: An overview. International Journal of Economics, Commerce and Management. 2014;2(11):1-22.

22. NEVO B. FACE VALIDITY REVISITED. Journal of Educational Measurement. 1985 Dec;22(4):287-293. https:// doi.org/10.1111/j.1745-3984.1985.tb01065.x

23. Yaghmaei F. Content validity and its estimation. 2003.

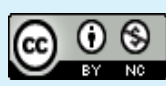

This work is licensed under a Creative Commons AttributionNon Commercial 4.0 International License. 